\title{
Diagnosis of a multifocal B cell lymphoma with preceding demyelinating central nervous system lesions by single voxel proton MR spectroscopy
}

\author{
T Kuhlmann, A Schröter, P Dechent, F Weber, H H Rustenbeck, L Füzesi, W Brück, \\ H Ehrenreich, J Frahm
}

\begin{abstract}
Single voxel proton magnetic resonance spectroscopy (MRS) provides a rapid non-invasive fingerprint of tissue chemistry. A case history is presented in which a $B$ cell lymphoma with antecedent demyelinating lesions of the CNS was suspected by MRS and confirmed by neuropathological examination and immunoglobulin gene rearrangement.

(F Neurol Neurosurg Psychiatry 2001;70:259-262)
\end{abstract}

Keywords: CNS lymphoma; magnetic resonance spectroscopy; demyelination

Primary lymphomas of the CNS are rare malignant tumours accounting for less than $1 \%$ of all brain tumours. Occasionally, primary CNS lymphomas are heralded by demyelinating lesions (sentinel lesions) which are histologically indistinguishable from multiple sclerosis lesions. ${ }^{1-3}$ Based on clinical and neuroradiological findings, differential diagnosis is often impossible. Localised proton magnetic resonance spectroscopy (MRS) has been successfully applied to a large variety of brain disorders in children and adults. ${ }^{4}$ Its ability to non-invasively identify alterations of cerebral metabolites that are specific for certain pathological processes such as damage of neuroaxonal tissue or proliferation of glial cells may provide a more sensitive tool for differential diagnosis. We report on a patient in whom proton MRS helped to distinguish between a demyelinating disorder and the occurrence of a primary CNS lymphoma.

Biomedizinische NMR Forschungs GmbH, Am Faßberg 11, Max-Planck-Institut für Biophysikalische Chemie, 37077 Göttingen, Germany P Dechent

J Frahm

Correspondence to: Professor J Frahm jfrahm@gwdg.de

Received 25 May 2000 and in final form

12 October 2000

Accepted 20 October 2000

CASE REPORT

In April 1998, a previously healthy 65 year old man developed vertigo, neck pain, recurrent vomiting, and gait disturbance. Cranial CT and MRI disclosed a tumour-like, diffusely gadolinium enhancing, hypointense (T1 and T2 weighted MRI) structure in the left cerebellar hemisphere (fig $1 \mathrm{~A}$ and B). The lesion was surgically removed and classified as a typical multiple sclerosis demyelinating lesion. Perioperative treatment with dexamethasone $(3 \times 8 \mathrm{mg}$ daily) starting 3 days preoperatively, led to rapid improvement of the patient's neurological functions. At the end of August 1998, the patient experienced pain and paresis of the left leg in addition to a recurring disturbance of balance. Brain MRI demonstrated new contrast enhancing lesions in the parieto-occipital white matter and in the right thalamus. Lumbar CSF showed pleocytosis and mildly increased protein $(0.7 \mathrm{~g} / \mathrm{l})$ but no oligoclonal bands. Symptoms diminished and MRI showed a reduced number of lesions under high doses of prednisolone. Tapering of corticosteroids rapidly enhanced the left spastic hemiparesis. In November 1998 MRI showed multiple, partly hyperintense, contrast enhancing lesions in both hemispheres and the brainstem. Three weeks after cessation of corticosteroid treatment, whole body CT, repeated bone marrow and lumbar punctures, and many serological analyses were performed yielding no evidence of a systemic lymphoma, or infectious or autoimmune disease. Visually and acoustically evoked potentials showed pathological changes. Again, treatment with prednisolone (100 mg/day) improved neurological functions and MRI lesions. During slow reduction of steroids in January 1999, MRI documented a large contrast enhancing lesion in the right parietal white matter and basal ganglia with surrounding oedema. Serum analysis showed the presence of antibodies directed against myelin oligodendrocyte glycoprotein (MOG); MRS demonstrated very high contributions of mobile lipids as a diagnostic hallmark. In a brain biopsy of this newly developed lesion, diagnosis of a B cell lymphoma was made. The patient was treated with prednisolone, methotrexat, and radiation. The clinical situation of the patient deteriorated rapidly. He died 2 months after the diagnosis of lymphoma due to pulmonary complications. A postmortem examination was refused by the relatives.

\section{HISTOPATHOLOGICAL FINDINGS}

In the cerebellar lesion surgically removed in April 1998 changes were restricted to the white matter, which was infiltrated by macrophages and $\mathrm{T}$ cells (fig $2 \mathrm{~A}$ ). Lymphocytes-among them many CD8 positive $\mathrm{T}$ cells-diffusely infiltrated the lesions (fig $2 \mathrm{~A}$ ). Plasma cells were rarely seen. Luxol fast blue myelin stain 
showed a demyelinated lesion. Immunocytochemistry with antibodies to the myelin proteins MBP and CNP disclosed thin myelin sheaths occasionally surrounding axons indicating remyelination (fig $2 \mathrm{~B}$ ) as well as a mainly preserved oligodendrocyte population (fig 2 C). Axons were reduced in number (Bielschowsky stain). In the biopsy from the right parietal lesion in January 1999, tissue was severely infiltrated by atypical, highly pleomorphic lymphoid cells with large nuclei (fig $2 \mathrm{D}$ ). Immunohistochemical studies with antibodies to B lymphocytes (anti-L26 and anti-CD79a) showed a monoclonal B cell population (fig 2 E) with high proliferative activity (immunocytochemistry against the proliferation associated antigen Mib-1). Ebstein-Barr virus antigen was not detected.

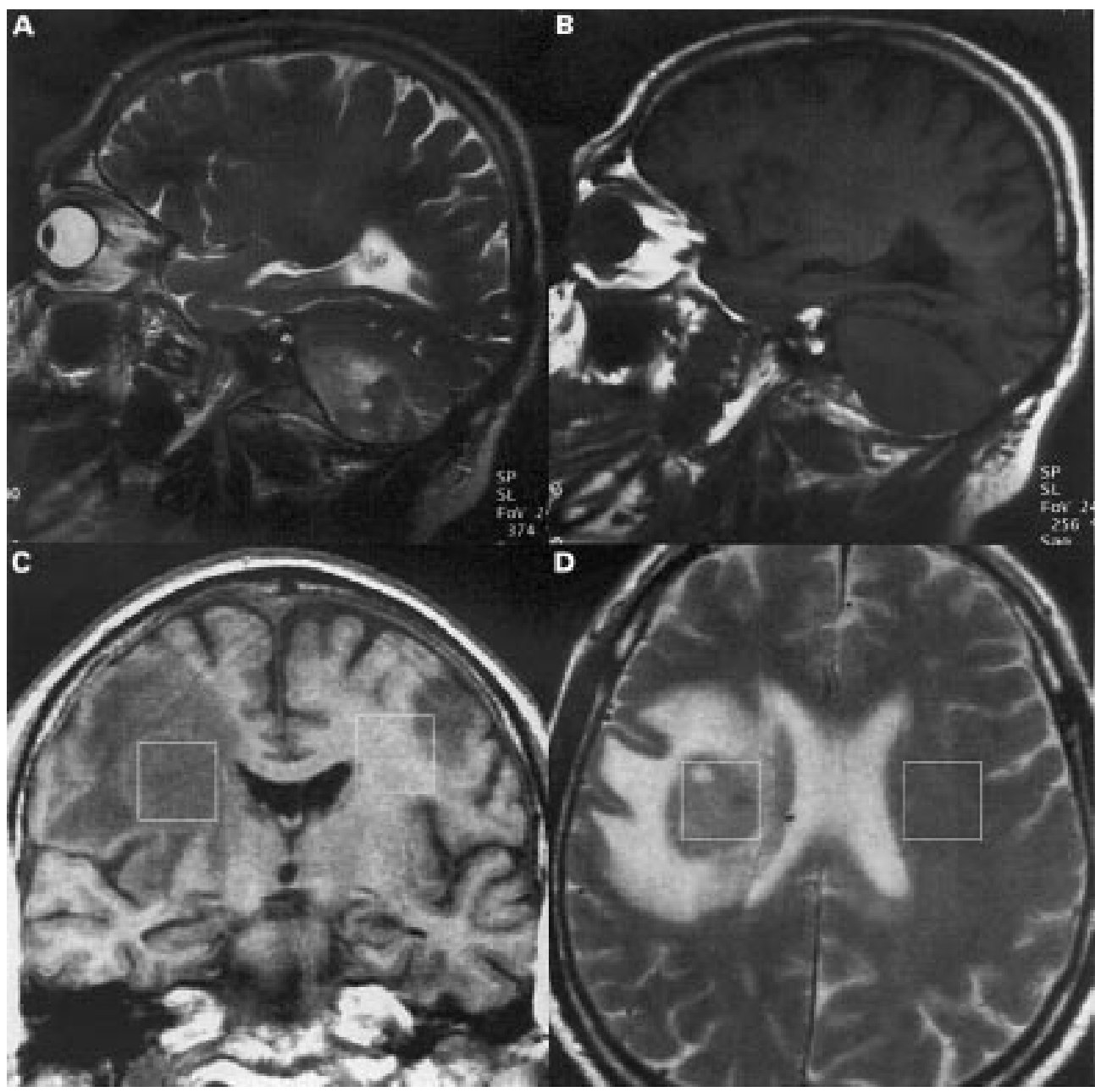

$\mathrm{E}$
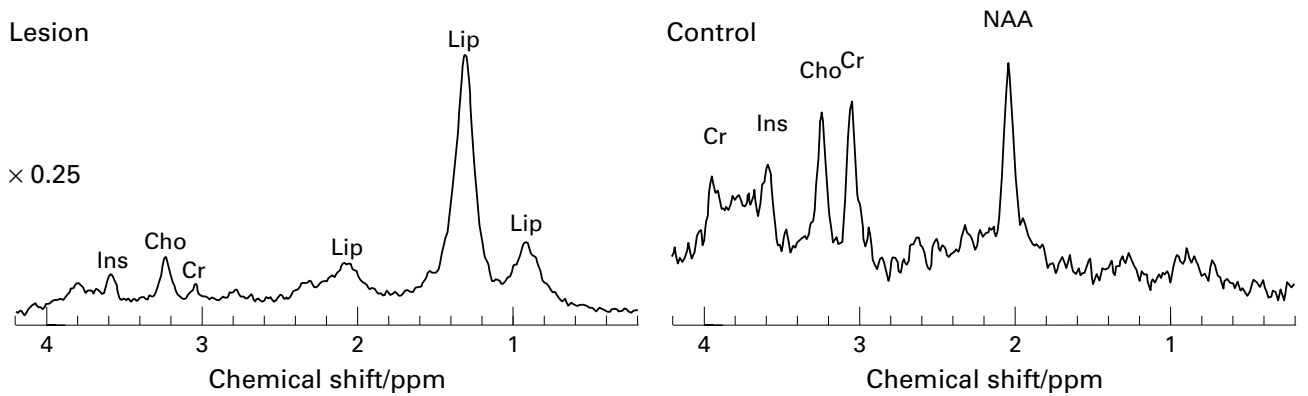

Figure 1 MRI and proton MRS. The initial cerebellar lesion was hypointense $(A)$ in T2 weighted images $(B)$ and T1 weighted images. (C) and D) show a secondary cerebral lesion. (C) T1 weighted ( $3 D$ FLASH, TR/TE $=15 / 4 \mathrm{~ms}$, flip angle $20^{\circ}$ ) and (B) T2 weighted MR image (FSE, TR/TE $=2625 / 98 \mathrm{~ms}$, fip angles $90 / 120^{\circ}$ ) of a transverse section (thickness $4 \mathrm{~mm}$ ) through the cortex indicating volumes of interest $(8.65 \mathrm{ml})$ selected for proton MRS. (E and $F$ )

Corresponding proton MR spectra (STEAM, TR/TE/TM =6000/20/10 ms, 64 accumulations) of the right parietal lesion (scaled down by a factor of four) and from a homologous area in the contralateral hemisphere, respectively. Metabolite resonances include $\mathrm{N}$-acetylaspartate and $\mathrm{N}$-acetyl aspartylglutamate (NAA), creatine and phosphocreatine (Cr), choline containing compounds (Cho), myoinositol (Ins), and mobile lipids (Lip). Whereas the contralateral control exhibits normal metabolite concentrations, the lesion is characterised by raised Cho and Ins as well as very high concentrations of mobile short chain fatty acids. 
POLYMERASE CHAIN REACTION (PCR) FINDINGS DNA was extracted from the paraffin blocks of both biopsies. For the determination of immunoglobulin gene rearrangement, a seminested PCR was performed as described in detail earlier. ${ }^{6}$ The Raji cell line CCL served as a positive control for the PCR. Electrophoresis of the PCR products disclosed a distinct DNA band of $90 \mathrm{bp}$ size in the second biopsy whereas the first biopsy did not show immunoglobulin rearrangement (fig $2 \mathrm{~F}$ ). There was no indication of $\gamma$-T cell receptor rearrangement in either biopsy.

\section{SPECTROSCOPY}

Localised proton MRS was performed at 2.0 Tesla (Siemens Magnetom Vision, Erlangen, Germany) using the standard imaging headcoil. Volumes of interest (VOI) for single voxel proton MRS of the right hemispheric lesion and a contralateral control region were selected from $\mathrm{T} 1$ and $\mathrm{T} 2$ weighted MR images (fig $1 \mathrm{C}$ and D). Fully relaxed short echo time proton MR spectra were acquired with use of a stimu- lated echo acquisition mode localisation sequence (STEAM, TR/TE/TM=6000/20/10 $\mathrm{ms}, 64$ acquisitions) as described previously. ${ }^{78}$ Automated user independent quantification of absolute metabolite concentrations in $\mathrm{mmol} / \mathrm{l}$ VOI ( $\mathrm{mM}$ ) was obtained by LCModel using a data base of calibrated model spectra of all individual metabolites. ${ }^{9}$ By contrast with the lesion spectrum (fig $1 \mathrm{E}$ ), the contralateral side (fig $1 \mathrm{~F}$ ) showed a typical white matter pattern with concentrations of metabolites within normal ranges. The lesion was characterised by increased Cho $(2.15 \mathrm{mM})$ and Ins $(5.5 \mathrm{mM})$, reduced $\mathrm{Cr}(1.7 \mathrm{mM})$, and a complete loss of NAA as well as by very high concentrations of mobile lipids (Lip). These short chain fatty acids give rise to at least three different proton MR resonances reflecting the terminal methyl groups at about $0.95 \mathrm{ppm}$, the chemically equivalent methylene groups of the main acyl chain at about $1.25 \mathrm{ppm}$, and the $\alpha$ and $\beta$ methylene groups at $2.0-2.2 \mathrm{ppm}$. The observation of highly concentrated mobile lipids is an unusual spectroscopic finding. Comparable

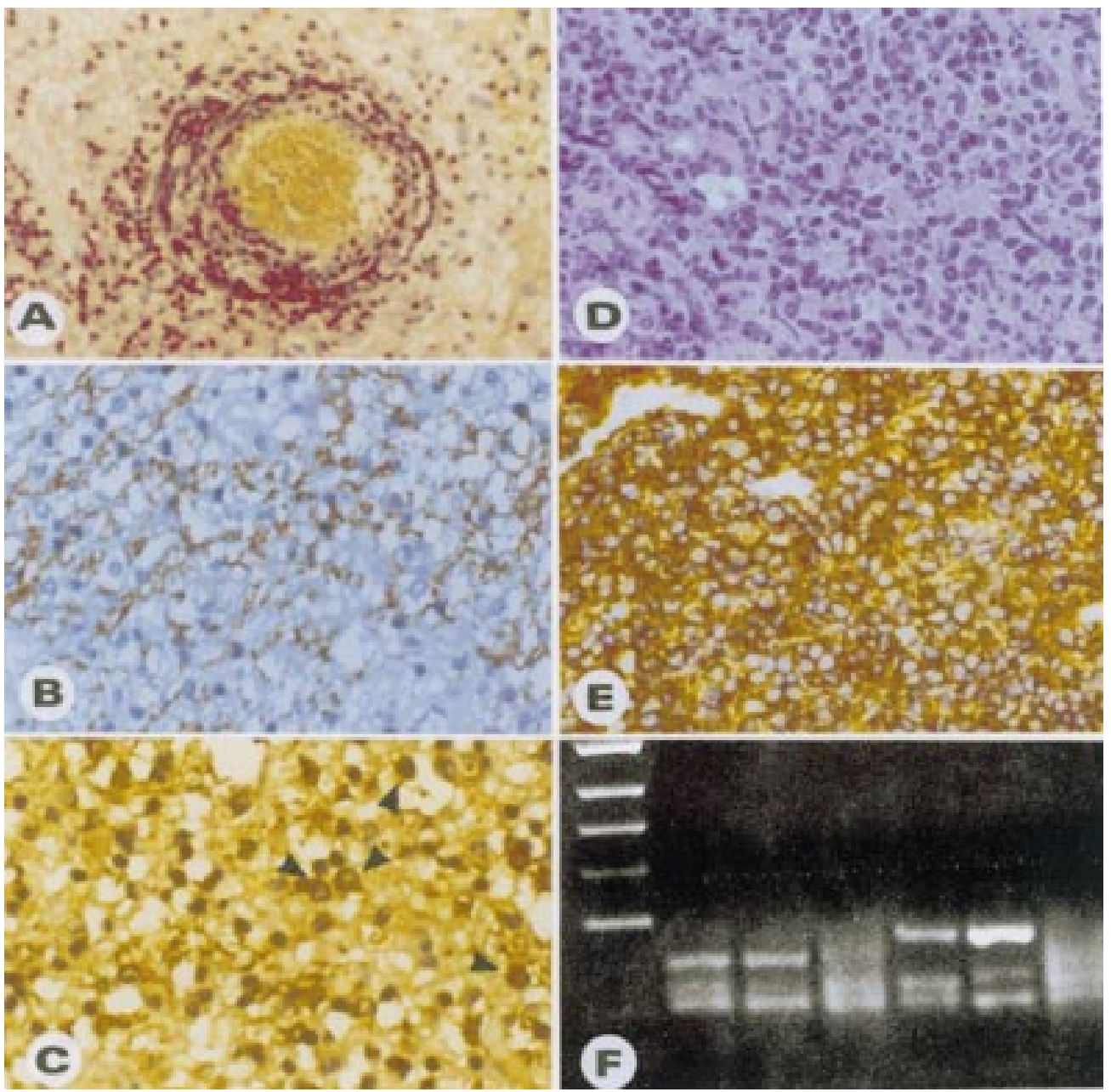

Figure 2 (A-C) Histopathological findings of the initial cerebellar lesion and (D and E) the right parietal lesion. (A) The initial lesion is infiltrated by numerous CD3 positive T cells. (B) The MBP stain disclosed demyelination and the presence of small clusters of uniform thin myelin sheaths indicative of remyelination. $(C)$ There were numerous CNPase positive oligodendrocytes (arrowheads) present in the lesion. (D) The right parietal lesion by contrast showed a highly cellular tumour consisting of atypical lymphoid cells. (E) Immunocytochemistry with the B cell marker CD20 shows a lymphoma consisting of a monoclonal B cell population. (F) DNA agarose gel after polymerase chain reaction analysis for immunoglobulin gene rearrangement. Lane 1=length standard; lanes 2 and $3=$ positive controls (EB-1 and CCL) showing the distinct 90 bp band; lane 4=normal lymph node without any monoclonal band; lanes 5 and $6=$ second biopsy with distinct 90 bp bands; lane 7=first biopsy showing no monoclonal band. 
lipid contributions have only been found in abscesses, lipoma, malignant glioblastoma, and primary CNS lymphoma. Most importantly, however, they are clearly distinct from the MRS correlates of neuroaxonal damage and gliosis found in demyelinating lesions. Together with the MRI appearance and in line with a recent MRS report of a lymphoma, ${ }^{10}{ }^{11}$ proton MRS of the lesion suggested a lymphoma.

\section{Discussion}

Subsequent to a single multiple sclerosis-like demyelinating lesion in the cerebellum a previously healthy 65 year old man developed multifocal contrast enhancing, steroid sensitive lesions. Nine months after the first symptoms a primary CNS lymphoma was suspected by MRS. A second brain biopsy confirmed the diagnosis of a primary CNS lymphoma by immunocytochemistry and immunoglobulin gene rearrangement. Primary CNS lymphoma with antecedent demyelinating lesions has been documented in several case reports. ${ }^{1-3}$ The pathogenesis of these sentinel lesions and their relation with the later developing lymphomas remain unclear. Primary CNS lymphomas are known to be massively infiltrated by $\mathrm{T}$ cells, ${ }^{12}$ and this feature may lead to the misdiagnosis of an inflammatory process. However, in our patient a hidden lymphoma in the first biopsy was excluded by molecular and immunohistochemical tools. The low dose steroid therapy which was started 3 days before the first biopsy might have affected the cerebellar lesion and led to regression of the tumour. ${ }^{13}$ However, it is unlikely that the malignant B lymphocytes were selectively eliminated and the surviving reactive $T$ cells within the tumour mimicked a demyelinating lesion.

The common appearance of demyelination and lymphoma may be the result of one causative agent. Numerous viruses have been associated with the pathogenesis of multiple sclerosis and the development of CNS lymphomas. In our patient, neither increased virus titres in $\mathrm{CSF}$, or serum, or virus antigen (EBV) within the biopsies were detected, making a virus associated pathogenesis unlikely. Alternatively, lymphocytic infiltrates accompanying leukoencephalopathies may have been transformed to malignant B cell lymphomas. ${ }^{14}$ In our case, antibodies to MOG were detected in the serum of the patient. These anti-MOG antibodies may be produced by transformed $\mathrm{B}$ cells and promote autoimmune demyelination. ${ }^{15}$ The clonal expansion of $\mathrm{B}$ cells from CSF in patients with multiple sclerosis supports the hypothesis of a possible transition of the inflammatory infiltrate to a malignant lymphoma. ${ }^{16}$

Discrimination between a demyelinating lesion and a tumour may be impossible with clinical and neuroradiological methods. Proton MRS measures metabolic profiles as a correlate of normal and pathological tissue composition or function and may thus aid in the differential diagnosis. MR Spectra of multiple sclerosis plaques are characterised by reduced NAA concentrations reflecting neuroaxonal damage as well as increased Cho and Ins concentrations indicating glial proliferation or the development of gliotic scars. MRS reports of moderately increased "lipid" signals in acute multiple sclerosis plaques have been described. ${ }^{17}$ On the contrary, primary CNS lymphomas show markedly decreased NAA, increased Cho and Ins, and very pronounced contributions from short chain fatty acids. ${ }^{10}$ Resonances due to mobile lipids have also been detected in other brain tumours such as astrocytomas, ${ }^{18}$ and it is suggested that they are derived from tissue necrosis, an uncommon feature of demyelinating CNS lesions. In summary, the present case demonstrates the potential of proton MRS for the in vivo differential diagnosis of demyelination versus CNS lymphoma.

1 Brecher K, Hochberg FH, Louis DN, et al. Case report of unusual leukoencephalopathy preceding primary CNS lymphoma. F Neurol Neurosurg Psychiatry 1998;65:917-20. Alderson L, Fetell MR, Sisti M, et al. Sentinel lesions of primary CNS lymphoma. F Neurol Neurosurg Psychiatry 1996;

3 Kuroda Y, Kawasaki T, Haraoka S, et al. Autopsy report of primary CNS B-cell lymphoma indistinguishable from multiple sclerosis: diagnosis with the immunoglobulin gene rearrangements analysis. F Neurol Sci 1992;111:173-9.

4 Frahm J, Hanefeld F. Localized proton magnetic resonance spectroscopy of brain disorders in childhood. In: Bachelard HS, ed. Magnetic resonance spectroscopy and imaging in neurochemistry. New York: Plenum Press 1997:329-402.

5 Danielsen ER, Ross B. Magnetic resonance spectroscopy diagnosis of neurological disease. New York: Dekker, 1999.

6 Wan JH, Sykes PJ, Orell SR, et al. Rapid method for detecting monoclonality in B cell lymphoma in lymph node aspirates using the polymerase chain reaction. $f$ Clin Pathol 1992;45:420-3.

7 Frahm J, Michaelis T, Merboldt KD, et al. Improvements in localized ${ }^{1} \mathrm{H}-\mathrm{NMR}$ spectroscopy of human brain. Water suppression, short echo times, and $1 \mathrm{ml}$ resolution. f Magn Reson 1990;1990:464-73.

8 Pouwels PJW, Frahm J. Regional metabolite concentrations in human brain as determined by quantitative localized proton MRS. Magn Reson Med 1998;39:53-60.

9 Provencher SW. Estimation of metabolite concentrations from localized in vivo proton NMR spectra. Magn Reson Med 1993;30:672-9.

10 Chinn RJS, Wilkinson ID, Hall-Craggs MA, et al. Toxoplasmosis and primary central nervous system lymphoma in HIV infection: diagnosis with MR spectroscopy. Radiology 1995;197:649-54.

11 Boyko OB. Adult brain tumors. In: Stark DD, Bradley WG, eds. Magnetic resonance imaging. St Louis: Mosby, 1998: 1231-54.

12 Bashir R, Chamberlain M, Ruby E, et al. T-cell infiltration of primary CNS lymphoma. Neurology 1996;46:440-4.

13 Todd II FD, Miller CA, Yates AJ, et al. Steroid-induced remission in primary malignant lymphoma of the central remission in primary malignant lymphoma

14 Hanto DW, Frizzera G, Gajl-Peczalska KJ, et al. EpsteinBarr virus-induced B-cell lymphoma after renal transplantation. N Engl F Med 1982;306:913-18.

15 Storch MK, Stefferl A, Brehm U, et al. Autoimmunity to myelin oligodendrocyte glycoprotein in rats mimics the pectrum of multiple sclerosis pathology. Brain Pathol 1998;8:681-94.

16 Qin Y, Duchette P, Zhang Y, et al. Clonal expansion and somatic hypermutation of $\mathrm{V}_{\mathrm{H}}$ genes of $\mathrm{B}$ cells from cerebrospinal fluid in multiple sclerosis. F Clin Invest 1998; 102:1045-50.

17 Davie CA, Barker GJ, Tofts PS, et al. Detection of myelin breakdown products by proton magnetic resonance specbreakdown products by proton mag
troscopy. Lancet 1993;341:630-1.

18 Frahm J, Bruhn H, Hänicke W, et al. Localized proton NMR spectroscopy of brain tumors using short-echo time STEAM sequences. F Comput Assist Tomogr 1991;15:915- 